\title{
ALGUNOS PROBLEMAS DE AUTORÍA Y EDICIÓN EN EL TEATRO DEL PRIMER RENACIMIENTO
}

\author{
Miguel ÁNGel Pérez Priego \\ Universidad Nacional de Educación a Distancia
}

A Jesús Cañas, en su jubilación académica

\begin{abstract}
Resumen
En general, sabemos poco de la biografía de los autores de nuestro primer teatro. De la mayoría de las decenas de autores de autos, farsas y comedias de la época, apenas si tenemos un nombre despojado de toda noticia. Se proponen aquí algunos modelos para investigar en esas lagunas e intentar reconstruir los datos biográficos que contribuyan a explicar mejor aquellas obras. En cuanto a los problemas de edición, se analizan los dos procedimientos principales de transmisión entonces del texto dramático, el de la compilación en libro de obra completa (Cancionero de Encina, Propalladia de Naharro) o el más frecuente de la impresión en pliego suelto, favorecida por la brevedad y provisionalidad de las obras.

Palabras clave: teatro del Renacimiento, biografía, crítica textual, imprenta, pliegos sueltos.

\section{SOME AUTHORING AND EDITING PROBLEMS IN THE THEATER OF THE FIRST RENAISSANCE}

\begin{abstract}
In general, we know little about the biographies of the authors of our first theater. Of most of the dozens of authors of 'autos', farces and comedies of the time, we hardly have a name stripped of all news. We propose here some models to investigate these gaps and try to reconstruct the biographical data that contribute to better explain those works. As for the problems of editing, the two main procedures of transmission of the dramatic text are analyzed, that of the compilation in book of complete works (Cancionero by Encina, Propalladia by Naharro) or the most frequent one of printing in 'pliego suelto', favored by the brevity and provisional nature of the plays.

Keywords: Renaissance theater, biography, textual criticism, printing, 'pliegos sueltos'.
\end{abstract}


El cambio más profundo que se produce en el paso del teatro medieval al del Renacimiento es el de la transformación de un teatro ritual, de ceremonia, en un teatro artístico, lo que conlleva la sustitución de las viejas formas representacionales (ludi theatrales, misterios, pasiones, momos) por los nuevos géneros de la égloga, la comedia o la tragedia. Con el Renacimiento, el teatro deja de ser rito y se convierte en espectáculo y arte, fija su texto en escritura y se carga de literatura. Muchas veces lo escriben poetas de renombre (Juan del Encina, Gil Vicente, Torres Naharro) y lo difunde la imprenta.

No obstante, si bien lo consideramos, la personalidad de la mayoría de los escritores de este teatro del siglo XVI nos es bastante desconocida. Sabemos algo de algunos más nombrados, como los citados, aunque muchos aspectos de su biografía se nos quedan en la más oscura penumbra. De algunos sabemos su condición de músicos y poetas, como Juan del Encina (1469-1529), que por eso se abre paso en las cortes de Alba, de los Reyes Católicos y luego en las de los papas Alejandro VI y Julio II. Poeta y dramaturgo, un tanto bullicioso y bohemio, sin oficio ni dedicación fija, hubo de ser Bartolomé de Torres Naharro (ca 1485-ca 1520) en Roma, donde frecuentó todos los ambientes y pudo observar con detalle las alegrías y miserias de los estamentos inferiores de aquella sociedad. De condición eclesiástica y bachiller en artes es Diego Sánchez de Badajoz ( ca 1490-ca 1550), cura de Talavera la Real, que alternó sus deberes pastorales con el verso y produjo un teatro catequístico entre burlas y veras. También bachiller y maestro de humanidades, que ejercería la enseñanza en lugares diversos, es Hernán López de Yanguas (ca 1487-ca 1550). Más oscura y algo agitada parece la biografía del placentino Micael de Carvajal (1500-1578), de quien, aparte de escribir la Tragedia Josefina, sabemos por algún documento que anduvo en pleitos familiares por el mantenimiento de su hacienda. Tras estudiar cánones y derecho en Salamanca, encerrado en su Toledo natal se nos muestra Sebastián de Horozco ( ca 1510-ca 1578), que ejerció cargos administrativos y ofició de literato y de cronista de asuntos locales. De la vida de Luis de Miranda (ca1505-ca 1580), autor de la Comedia pródiga, apenas sabemos por un poema, en el que habla de su partida de Plasencia y de sus aventuras, y por un romance que lo sitúa en la conquista del Río de la Plata y que lo convierte en el primer poeta de Buenos Aires, como lo evoca en un magnífico relato Manuel Mujica Láinez (1974: 17-22). 
Pero de la inmensa mayoría de los autores de autos, farsas y comedias de la época, apenas si tenemos un nombre despojado de toda noticia. Hay decenas de nombres, que conocemos por los repertorios de Hernando Colón, Cayetano Alberto de la Barrera, Manuel Cañete o Emilio Cotarelo ${ }^{1}$, la mayoría autores de una sola pieza, de los que apenas ha quedado noticia (Alonso de Salaya, Andrés Ortiz, Juan de Melgar, Diego de Guadalupe, Jaime de Güete, Francisco de las Natas). Investigar en esas lagunas e intentar reconstruir datos biográficos que contribuyan a explicar mejor aquellas obras es una apasionante aventura y un terreno en el que todavía queda mucho por hacer y al que modestamente vengo dedicando algunos esfuerzos. Pondré algunos ejemplos.

Casi imposible es identificar al Fernando Díaz, autor de una breve Farsa del Nascimiento, en coplas de arte mayor, publicada en Burgos en 1554. Nada en particular dice el texto conservado y, al tratarse de un nombre y apellido muy comunes, no sabríamos qué Fernando o Hernando Díaz es este. En el terreno de la mera conjetura, podría pensarse en Hernando Díaz, conocido y fecundo traductor por aquellos años de Walter Burley, de Séneca, de Caviceo y especialmente de la Commedia de Dante, a cuya traducción se dedicó durante varios años en Salamanca, pero de la que sólo publicó seis coplas de arte mayor, correspondientes a los comienzos de cada uno de los tres cantos. Esa fidelidad al verso de arte mayor es la que compartiría con el autor homónimo de la Farsa del nascimiento (Pérez Priego, 2012).

Semejante es el caso de la Farsa nuevamente compuesta por Juan de París, conocida por un pliego suelto de 1536 y por otro perdido de 1551 . Nada sabemos de ese Juan de París, que es nombre que existía en la época, pero sin conexión con la farsa. Del texto se desprende que Juan de París conocía la tradición del teatro pastoril y, en particular, la obra de Juan del Encina, que era un autor culto con formación clásica, y que adopta un tono admonitorio y doctrinal que pone de manifiesto el pensamiento religioso del autor y tal vez su condición de hombre de iglesia. Es muy probable, por tanto, que se trate de un clérigo cultivado que compone una breve pieza dramática para celebrar un casamiento, con exaltación más o menos explícita del matrimonio, pero cuidando de ocultar o velar su propia identidad. Por lo demás, Juan de París es el nombre de

\footnotetext{
${ }^{1}$ Véanse Colón (1992), Barrera Leirado (1860), Cañete (1885), Cotarelo Mori (1902).
} 
un célebre teólogo dominico del siglo XIV, maestro de la Sorbona, que, aparte de otras ideas, es conocido por su defensa de la limitación del poder terrenal del papado y la iglesia. Pudiera ser, el de Juan de París, un nombre adoptado por el autor de nuestra farsa, como una especie de seudónimo, un tanto irónico y jocoso, acorde con la condición de farsa de la obra (Pérez Priego, 2018).

Enigmático es también el Salazar de la Égloga de Salazar, de Breno y otros tres pastores, sobre el casamiento del duque de Medinaceli con la hermana del conde de Cifuentes. La obra aparece ya mencionada en el Abecedarium de H. Colón, aunque introduciendo confusión sobre el nombre del autor («Salazar de breno egloga al duque de medina celi...»), por lo que durante siglos se ha hablado de Salazar de Breno (Breño) como autor de la farsa, asignándole un segundo apellido que no es sino el nombre de uno de los personajes de la obra. No cabe ninguna duda de que son dos nombres distintos: Salazar, el del autor, y Breno, uno de los pastores. De este Salazar no sabemos nada con seguridad. Es un apellido bastante común que, en esos años, sin ir más lejos, lo encontramos relacionado tanto con la casa de Medinaceli (un Alonso López de Salazar era escribano del duque y notario de Medinaceli) como con los condes de Cifuentes (un Fabián de Salazar al que le conceden la villa de Renales por su intervención en el matrimonio). Cabe pensar que el autor de la égloga, al que hay que suponer formación letrada, había estado al servicio de la casa ducal y allí, aparte de realizar funciones administrativas, ejercería de poeta y de animador literario de fiestas y ceremonias. Una de esas ocasiones sería esta del segundo casamiento de don Luis de la Cerda (viudo de doña Mencía Manuel de Portugal, hija de don Afonso de Portugal, conde de Faro y Mira, muerta de sobre parto en 1504), ocasión para la que escribió una pequeña pieza teatral (Pérez Priego, 2013).

La obra Tres Pasos de la Pasión y una Égloga de la Resurrección se hallaba en un facticio desaparecido de la Biblioteca de Menéndez Pelayo, de donde la editó Joseph E. Gillet en 1932, y del que se han conservado sólo algunos fotogramas. La pieza está falta de la primera hoja y sólo por el colofón conocemos el título así como el lugar y fecha de publicación (Burgos, Alonso de Melgar, 6 de abril de 1520). El nombre del autor figuraría seguramente en la portada, pero nos quedamos sin saberlo, y la obra se ha dado como anónima y hasta se ha llegado a atribuir al impresor Alonso de Melgar. Sólo revisando datos, casándolos y leyendo 
atentamente hemos podido avanzar más. En este caso, ayuda mucho el Abecedarium B, n. 12259, de Hernando Colón, donde aparece esta entrada: "Alfonsi de castrillo. contemplationes la [sic] passion con egloga de resurrectio. bu. 1520». El dato resulta del mayor interés, pues nos da un posible nombre de autor (Alfonsi de castrillo), autor de los pasos y égloga, sobre cuya identidad ahora podemos rastrear algunas noticias. Lo primero que descubrimos es que este Alfonso de Castrillo es el mismo autor del Tratado de república, también publicado en Burgos por Alonso de Melgar, el 21 de abril de 1520. El estilo, las fuentes manejadas, la forma de citarlas, aparte de la coincidencia de nombre, fecha, lugar e imprenta, no dejan dudas sobre la identidad de este Castrillo con el autor de los pasos.

Por este nuevo libro, tirando del hilo, conocemos que Alfonso de Castrillo era fraile trinitario, orden creada en el siglo XII para liberar y redimir cautivos cristianos. También comprobamos que el Tratado va dedicado a Fray Diego de Gayangos, del que sabemos fue provincial y reformador de la Orden, y buen aliado de la política de Carlos I, que le hizo miembro de su Consejo Real. El Tratado, sin embargo, a pesar de lo que se pudiera pensar por su título, es un libro más bien en defensa de la monarquía, en el que se alerta de los excesos comuneros y se defiende una sociedad armonizada y gobernada por el rey. Castrillo, en efecto, lo dedica a su reformador superior, que intervino en la guerra de las Comunidades, «buscando siempre el concierto y la conciliación a través de la elocuencia y de la palabra», y lo hace precisamente por aquellas fechas de 1521, en vísperas de la derrota de Villalar y cuando él profesaba en el convento de los trinitarios en Burgos. Conociendo ahora todos esos datos, pueden interpretarse mejor los Pasos y la Égloga, que se creían anónimos. Se entiende que vayan dirigidos a una desconocida y «muy devota señora», a la que se ofrecen como materia de contemplación y meditación, en la línea de las necesidades de una piedad más íntima que proclamaba el reformador de la orden. O se interpreta mejor la escena final, apoteósica, de la llegada de Cristo al infierno y el rescate de los cautivos en poder de Satanás, como evocación analógica de la propia labor redentora de la orden trinitaria, que rescata a cientos de cristianos de los poderes de los infieles, como en esos años estaba haciendo Fray Diego de Gayangos (Pérez Priego, 2011). 
En resumen, respecto de la autoría e identidad de los autores, no es mucho lo que vamos sabiendo, pero sí confirma un perfil autorial, el de autores de una sola obra, de formación letrada, vinculados a una corte nobiliaria o a un convento o parroquia, o a un ámbito culto, que quieren velar su nombre como autores de estas obras menores. La mayoría de las cuales son escritas para celebrar casamientos y tratar del matrimonio, que es ocasión de fiesta y representación y, desde el punto de vista doctrinal, cuestión debatida en la época.

En cuanto a la edición de los textos, comencemos diciendo que, frente al teatro medieval que se conservó mal y apenas fue recogido por escrito, con el Renacimiento el teatro aspira a hacerse memorable, monumento, por lo que pasa de la transmisión oral o la copia ocasional, a las técnicas de la transmisión escrita. Su texto es concebido literariamente, se escribe de una determinada manera (en una pautada escritura teatral, que distingue perfectamente rúbricas, didascalias, distribución de personajes y texto dialogado) y será, no ya sólo copiado, sino publicado y difundido por la imprenta.

Cabe señalar dos procedimientos principales de transmisión: el del pliego suelto y el de recopilación de obras completas. El primero es el más habitual: decenas de obras se han trasmitido en tiradas sueltas. El segundo es menos frecuente. Lo inicia Encina con su Cancionero de 1496, en el que recoge en apartado final ocho églogas dramáticas. Le siguen Lucas Fernández con sus Farsas y églogas de 1514, Torres Naharro en Italia, con una distribución mixta de poemas y piezas dramáticas en su Propalladia, continúa Sánchez de Badajoz (en realidad, su sobrino); en Portugal, Gil Vicente (su hijo); a Lope de Rueda lo editará Juan Timoneda en Valencia, mientras que Juan de la Cueva será la excepción de la generación de 1580 al editar él mismo sus comedias y tragedias en Sevilla en 1583. Cervantes tendrá que esperar a 1615 para editar sus comedias y entremeses, cuando ya goza de renombre y de independencia literaria.

Ese tipo de edición de obra completa fue muchas veces una auténtica empresa cultural. En el caso de Encina, su obra teatral va arropada por su obra poética, que conforma la mayor parte de su Cancionero, el cual se presenta además bajo la poderosa protección de los Duques de Alba, los Reyes Católicos y el Príncipe don Juan, a quienes, en sucesivos paratextos, dedica solemnemente la obra. Este Cancionero de las obras de 
Juan del Enzina se publica en Salamanca, el 6 de junio de 1496, edición cuidada y revisada por el propio autor, entonces aún residente en la ciudad. Y se hubo de convertir pronto en un buen negocio editorial, por lo que, con Encina ya ausente en Italia, se sucedieron varias ediciones. La primera en Sevilla, en 1501, por [Juan] Pegnitzer y [Magno] Herbst, a quienes se la encargaron los libreros sevillanos Lázaro de Gazanis y Guido de Leazaris. La siguiente fue la de Burgos, en 1505, por Andrés de Burgos, encargada por Francisco Dada y Tommaso Favario de Lumello, un mercader de libros de Pavía, que financia una obra de éxito publicada en España, que era un buen mercado editorial para libreros e impresores extranjeros, que abrían filiales o realizaban concretas operaciones especulativas. Otras dos ediciones posteriores se hacen en Salamanca, por Hans Gysser, en 1507 y 1509, que incorporarán nuevos textos encinianos, como la Égloga sobre los infortunios de las grandes lluvias y la Representación ante el príncipe don Juan sobre el poder del Amor, la de 1507, y la Égloga de Fileno, Zambardo y Cardonio y el Auto del repelón, la de 1509. En Salamanca, sin duda, estaba más fresco el recuerdo de la actividad poética de Encina, mantenido por admiradores y amigos. Un inquieto y avisado impresor como Gysser pudo recoger todavía textos que Encina había compuesto y representado antes de marchar de Salamanca, textos como el escenificado ante el Príncipe don Juan en 1497 o de ambiente estudiantil como el Auto del repelón. Y atento al nombre y a la fama de Encina, pudo incluso recoger o solicitar una obra compuesta ya en Italia como es la Égloga de Fileno, Zambardo y Cardonio. Lo que ya no pudo ocurrir es que Encina revisara estos textos. Él, que cuidó escrupulosamente la edición de su Cancionero de 1496 en la que se conoce como imprenta de la Gramática de Nebrija, ajustando la grafía del texto a las propuestas del gramático, particularmente en cuanto a acentuación y a puntuación (también es uniforme el criterio de separación de palabras, reducción de grupos consonánticos latinos, uso de $v$ interna), no intervino ya en la de estos otros textos en los que se deslizaron erratas de cajistas e impresores e intervenciones de correctores en la disposición de rúbricas y diálogo.

También en el caso de las obras de Bartolomé de Torres Naharro la edición es un paso ulterior a la representación. Sus comedias sabemos que se recitaban (es el término que él mismo emplea) en ambientes de la curia romana y que de ahí pasaron a la letra impresa. Así ocurrió con su 
comedia Tinellaria (de la que tenemos una suelta s.l. s.a., posiblemente en Roma, 1511-1516), que lleva al frente una dedicatoria en prosa al Cardenal de Santa Cruz, Bernardino de Carvajal. Allí se explica cómo era aquel proceso de ejecución literaria de la comedia, de la que había una copia de autor, un recitado y una estampación. Naharro efectivamente recuerda que después de recitada al Cardenal y a monseñor [Giulio de] Medici, su patrón, aquél le mandó que le diese la copia de la comedia y le preguntó la causa de por qué no dejaba a estampar lo que escribía. Entre sorprendido y disgustado, Naharro explica que no lo hizo porque nadie mayormente se interesaba por ello, pero que lo hará si se mantiene tal interés, como de hecho confirma la edición que ahora ofrece.

Tal vez animado por esos y otros requerimientos, Naharro decidirá publicar el conjunto de sus obras, en un volumen, al que da el título de Propalladia y en el que edita poemas (como antepastoy pospasto) y obras dramáticas. Sorprende, sin embargo, que no las edite en Roma. Quizá para evitarse complicaciones. En 1515 se había promulgado la bula Inter Sollicitudines, que prohibía imprimir cualquier libro sin la autorización del Maestro del Sacro Palazzo Apostolico (el 'teólogo del Papa' encargado de velar estrictamente de la doctrina cristiana, entonces Silvestro Mazzolini da Prierio) y del Tribunal local de la Inquisición, bajo pena de excomunión, confiscación y destrucción de las obras ofensivas a la religión católica. Naharro, consciente de que la sátira contra Roma de algunos de sus poemas podría dificultar aquella autorización, trataría de eludir los trámites y obstáculos inquisitoriales. Para ello, lo primero consigue el privilegio de León $\mathrm{X}$, probablemente por sus relaciones personales, pero sobre todo porque lo pagaría, como con frecuencia hacían los autores. Con el privilegio papal sería más fácil sortear un tribunal local, para lo que además busca en Nápoles la protección de Ferrante d'Ávalos, esposo de Vittoria Colonna, ambos muy comprometidos con todo lo español, a los que dedica y amparan la obra. El encargado de editarla es el impresor Jean Pasquet, de origen francés, establecido en Nápoles, donde desarrolla actividad entre 1517 y 1524, en una imprenta cerca de la iglesia de la Santissima Annunziata, en la calle de San Pietro. No parece que fuera ni muy bueno ni muy activo, pues son pocos los impresos que se le conocen y no descargados de errores. No pasando mucho tiempo, no se libraría Naharro de la persecución inquisitorial, que prohibiría la Propalladia en 
el índice de 1555 y luego, en 1573, autorizaría y promovería una edición expurgada.

Las obras de Diego Sánchez de Badajoz se han conservado en un ejemplar único, impreso en Sevilla, 1554, editadas por su sobrino Juan de Figueroa con el título de Recopilación en metro. Antes de esa fecha lo que habría serían copias manuscritas que se utilizarían para la representación de las farsas, ya fuera en Talavera, en Badajoz o en el palacio de Feria, en Zafra. De esa etapa manuscrita no ha sobrevivido nada ni sabemos qué materiales la constituirían, pero a partir de ellos el sobrino promovió la impresión de la obra completa de su tío ${ }^{2}$. Impresión que, conviene notarlo para entender mejor el curioso proceso de impresión, se lleva a cabo en unos años todavía de escaso control sobre la producción de libros, los comienzos de la década de los cincuenta, con Felipe II de regente, y antes de la famosa pragmática de 1558 sobre la producción y circulación de libros que exigía su presentación al Consejo Real y la licencia de este, tras el examen, rúbrica y cotejo de cada folio.

Nuestro libro, en efecto, lleva al frente una licencia en nombre del Príncipe (Felipe II), fechada en Toro el 23 de abril de 1552, expedida, a solicitud del dicho Juan de Figueroa, por el oficial Francisco de Ledesma. Aunque se alude de pasada al preceptivo examen del libro ( $Y$ porque, aviéndose visto por nuestro mandado el dicho libro, pareció que de imprimirse no se seguiría inconveniente, por la presente os damos licencia...»), cabría pensar que la licencia se otorgó más que sobre el libro mismo, sobre la relación o memorial presentado por Figueroa, como viene a sugerirlo el propio texto de la licencia:

Por quanto por parte de vos, Juan de Figueroa [...] nos ha sido fecha relación que el bachiller Diego Sánchez, vuestro tío ya difunto, dexó hecho un libro de ciertas obras intitulado Recopilación de farsas y sermones con un confesionario, y nos suplicastes y pedistes por merced que, teniendo

${ }^{2}$ Recopilación en metro / del bachiller Diego sánchez de badajoz, enla / qual por gracioso Cortesano y Pastoril estilo / se cuentan y declaran muchas figuras y auto / ridades dela sagrada escriptura Agora nueua / mente ympresso y Dirigido al yllustrissimo Se / ñor Don Gomez suarez de Figueroa Conde d' Feria etc. / Com priuillegio, 4 , 6+154 hs. [Al fin] Fue Impresso el presente libro / enla muy noble y leal ciudad de Seuilla / junto al meson de la castaña acabose / a ocho dias del mes de Otu / bre Año de mil y quini / entos y cinquenta / y quatro. Ejemplar único: Biblioteca Nacional de España, R-4868. Puede verse la edición crítica de Weber de Kurlat (1968). 
respeto al trabajo que el dicho vuestro tío tuvo en componer la dicha obra, os diésemos licencia [...] imprimir y vender las dichas obras en estos reinos y señoríos de Castilla [...], por la presente damos licencia y facultad [...].

Como se ve, aparte la imprecisión con que el texto se refiere al objeto («un libro», «de ciertas obras», «la dicha obra», «las dichas obras»), Figueroa solicita la licencia para un libro que probablemente no existía y que desde luego no es el que se publicó, que en ningún caso contenía aquellos sermones y confesionario que dice había escrito su tío, sino sólo las farsas y algunos poemas. Lo hace además astutamente, presentando esa solicitud no directamente al Consejo de Castilla, sino a través de una instancia eclesiástica, en Toro, jurisdicción del obispado de Salamanca, que como otros obispados y arzobispados estuvieron autorizados un tiempo para otorgar esas licencias de impresión. Esto ocurría desde la publicación de la bula papal Inter multiplices publicada por Inocencio VIII en 1487 dirigida a toda la cristiandad. En ella se alababan los beneficios de la imprenta como difusora de libros de provecho, pero se condenaba su utilización para difundir escritos perniciosos para la moral y la doctrina. Por ello se establecía la necesidad de la autorización eclesiástica por parte de los ordinarios de cada lugar, previo examen, para la impresión de cualquier libro. Para quienes no lo cumplieran, se decretaban penas de excomunión y una sanción económica. Esta potestad la perderían aquellos centros eclesiásticos con la ordenanza de Felipe II de 12 de julio de 1554, en La Coruña, y más rotundamente con la Pragmática de 1558.

La aparente condición piadosa y doctrinal del libro a que remitía el título (Recopilación de farsas y sermones con un confesionario), el trabajo tomado por el autor en componerlo (al que apela el solicitante), bachiller y ya difunto, facilitarían la concesión, por cédula real, de la licencia para que en exclusividad lo imprimiera y vendiera durante diez años en el reino de Castilla. Con esa cédula real de licencia y privilegio, Figueroa no se decidió a imprimir las obras de su tío en Salamanca, como quizá fuera su primera intención. Por el contrario, decidió reducir el libro a sólo piezas teatrales y algún poema, le cambió casi todo el título, ahora más prolijo y confuso (Recopilación en metro del bachiller Diego Sánchez de Badajoz, en la qual, por gracioso, cortesano y pastoril estilo, se cuentan y declaran muchas figuras y autoridades de la Sagrada 
Escriptura....), y buscó más prósperos mercados en la bulliciosa Sevilla, que vivía entonces una intensa actividad teatral.

Aunque dedicado pomposamente al conde de Feria ( he determinado de sacar el Cerbero del infierno con el ayuda de Hércules»), pues a él había servido su tío, Figueroa se hubo de ver en la necesidad de editar el libro a expensas de su propio peculio. No se dirigió entonces a los grandes impresores sevillanos (Cromberger, Montesdoca), sino a una imprenta barata y modesta, que operaba con material reusado y papel barato, que le haría una tirada de corto número de ejemplares. El libro salió así impreso «en la muy noble y leal ciudad de Sevilla, junto al mesón de la castaña», por toda referencia al nombre de imprenta, pero que Weber de Kurlat (1965-1966) identificó sagazmente como la imprenta de Juan Canalla o de sus herederos, que estaba en aquel lugar situada. El libro fue acabado "a ocho días del mes de otubre año de mil y quinientos y cincuenta y cuatro», a los pocos meses de que Felipe II hubiera quitado a los obispados la facultad de gestionar licencias de impresión.

De todos modos, no fue lo habitual que se realizase este tipo de recopilaciones, compilaciones, propalladias o cancioneros, en las que se recogiera en conjunto una producción teatral ${ }^{3}$. Lo más frecuente era la publicación de la obra dramática, dada su brevedad y provisionalidad, en pliegos y ediciones sueltas. Sus tiradas llegaron a hacerse por centenares de ejemplares, aunque la inmensa mayoría se han destruido con el paso del tiempo. En pliegos se publicaron muchísimas piezas religiosas (autos de Navidad, de Pasión y Resurrección o del Corpus Christi), al igual que comedias, églogas o farsas, tanto anónimas como de autores poco conocidos y de escasa producción. Era un tipo de edición un tanto efímera, acorde con lo circunstancial de la ocasión para la que la pieza se había escrito y se representaba. Para los talleres de imprenta no debía de ser mal negocio, pues a bajo coste, dejándolas muchas veces a cargo de los

\footnotetext{
${ }^{3}$ En manuscrito, por otra parte, es poco lo que nos ha llegado de este teatro: algún auto o farsa sacramental, alguna comedia y, quizá el ejemplo más notorio, las cuatro breves piezas teatrales de Sebastián de Horozco, representadas hacia mediados de siglo y copiadas en su Cancionero, difundido sólo en los círculos literarios toledanos. La transmisión manuscrita parece más tardía, de momentos de menor permisividad con el impreso teatral, y es un fenómeno más característico del teatro de la segunda mitad del siglo (son muestra el Códice de autos viejos y otros repertorios de autos, o la colección de comedias de la Biblioteca de Palacio, procedente de los fondos del conde Gondomar).
} 
aprendices y oficiales más jóvenes y utilizando materiales de baja calidad, satisfacían la demanda de un amplio público de lectores. Algunos de esos talleres, como el de Juan de Junta, en Burgos, en la década de los cincuenta, a mediados de siglo, editaron gran número de piezas dramáticas e incluso reiteraron ediciones anteriores (véanse los documentados estudios de Fernández Valladares, 2003: 7-23 y 2005).

La edición en pliegos sueltos ha originado muchos problemas de transmisión, puesto que casi siempre se han conservado en ejemplares únicos dispersos por bibliotecas de todo el mundo. Muchas veces se constituyeron volúmenes facticios, que sólo en ocasiones se han conservado y muchas otras se han perdido o se han desmembrado. De la Biblioteca Menéndez Pelayo de Santander desapareció un volumen, que contenía, entre otras obras, la del citado Castrillo y alguna de Yanguas, no sin que antes los ejemplares góticos que constituían el tomo hubiesen sido mutilados y cortados los grabados de la portada de cada obra. Sí se ha conservado el facticio de la Biblithèque de l'Arsenal de París, que contiene la égloga de Salazar, la de Plácida y Vitoriano de Encina o la Tinellaria de Naharro (Heaton, 1927). Otro, que perteneció a la biblioteca de Henri Ternaux-Compans, en París, con piezas como la égloga de López Rangel, la Radiana o las comedias de Jaime de Huete, fue desgajado y vendido pieza a pieza, aunque por fortuna la mayoría de ellas terminaron en la Biblioteca Nacional de España.

Quizá el caso más curioso y significativo es el de un volumen facticio que se custodiaba en la Bayerische Staatsbibliothek, Rar. 273 (11), en Múnich, de la que al parecer desapareció en el curso de la Segunda Guerra Mundial (Pérez Priego, 2017). El volumen contenía catorce piezas dramáticas impresas muy importantes (Florinea, Tragicomedia alegórica del paraíso y del infierno, Aquilana, Tidea, Tesorina, Florisea, Tragedia Policiana, Égloga pastoril, Égloga nueva, Farsa de la danza de la muerte, Farsa del mundo y moral de López de Yanguas, Farsa de Fernando Díaz, Farsa de Juan de París, Farsa salamantina). Las obras procedían de la rica biblioteca del banquero y bibliófilo Johann Jakob Fugger, sobre la que se formó la Staatsbibliothek. El banquero Fugger, que mantuvo continuos negocios en Castilla (la explotación de las minas de mercurio de Almadén, por ejemplo) y con Carlos V, él mismo o por medio de sus emisarios y agentes, entre otros muchos bienes suntuarios, fue adquiriendo una rica colección de libros y pliegos sueltos teatrales que fue 
depositando en su biblioteca. La adquisición hubo de hacerse en torno a los años cincuenta del siglo XVI, por lo que la mayoría de las piezas son impresiones salidas de los talleres de Juan de Junta en Burgos. No deja de ser llamativa esta circunstancia de que sean obras publicadas en un mismo tiempo y en un mismo taller. Daría la impresión de que han sido adquiridas de un almacén tipográfico, con la tinta todavía fresca, en una sola compra y de manera simultánea. Lo más sencillo sería así pensar que se adquirieran en el almacén de Juan de Junta, pero no es seguro. Muchas otras obras existían por aquellos años en ese almacén y en un inventario de 1552 sólo aparece registrada una de nuestra colección. Tampoco consta que hubiera una relación comercial entre los banqueros y el impresor, como en el caso de otros impresores. De manera que lo más probable es que fueran adquiridas por sus agentes, que estarían en contacto con distintos centros libreros y sobre todo frecuentarían las ferias comerciales, que fueron importante foco de distribución y venta del libro, con afluencia de libreros, editores y agentes comerciales de todo el mundo. De las piezas dramáticas de la colección, si no puede asegurarse que se hayan seleccionado con un riguroso criterio literario, no deja de ser significativo que allí estén representadas las formas y géneros principales por los que discurría el teatro de la primera mitad del siglo XVI, del auto a la comedia o de la égloga a la farsa.

El volumen, como decimos, se da por destruido en los bombardeos de la guerra. Misteriosamente, sin embargo, han ido apareciendo con posterioridad algunas de las piezas que lo integraban. En una desconocida biblioteca particular de Cagliari (Cerdeña, Italia) se halla al parecer el ejemplar de la Farsa llamada dança de la muerte, del que con todo sigilo se hizo una edición y un facsímil en 1992 (Karlinger y Pögl, 1992). El ejemplar de la Comedia Aquilana fue adquirido en subasta pública por la Biblioteca Nacional de España en 2011. En 1969 el profesor chileno Ricardo Benavides Lillo editó la Comedia Florisea teniendo a la vista, aunque no lo confiesa, el volumen de Múnich (Benavides Lillo, 1969). De manera sorprendente, sin embargo, ese mismo ejemplar de la Florisea ha aparecido registrado e incluso digitalizado en la página de la Biblioteca Universitaria de Augsburg, donación del profesor [Günther] Haensch, lexicógrafo y catalanista. Todo hace pensar que el volumen no fue destruido, sino que sobrevivió al menos parcialmente y que en aquellos tiempos de guerra algunos soldados o profesores alemanes pudieron tener 
acceso a él o a alguna de sus partes. Reconstruir filológicamente, si es que no hallarlo materialmente, es todo un desafío para la investigación literaria y teatral.

\section{BIBLIOGRAFÍA CITADA}

BARRERA LEIRADO, C. A. de la (1860): Catálogo bibliográfico y biográfico del teatro antiguo español, desde sus orígenes hasta mediados del siglo XVIII. Madrid: M. Rivadeneyra.

BENAVIDES LILLO, R. (1969): «Francisco de Avendaño y el teatro renacentista español». Boletín de Filología. Universidad de Chile, 12, 51-164.

CAÑETE, M. (1885): Teatro español del siglo XVI. Estudios histórico-críticos. Madrid: [s.n.].

Colón, H. (1992): Abecedario B y Suplementum. Madrid: Mapfre América (ed. facsímil).

Cotarelo Mori, E. (1902): Teatro español anterior a Lope de Vega. Catálogo de obras dramáticas impresas pero no conocidas hasta el presente. Madrid: Impr. Felipe Marqués.

FERNÁNDEZ VALLADARES, M. (2003): «Un taller de imprenta para la Farsa llamada dança de la muerte: Burgos como foco difusor del teatro de cordel en el siglo XVI». Revista de Filología Románica, 20, 7-23.

FERNÁNDEZ VALladARES, M. (2005): La imprenta en Burgos (1501-1600). Madrid, Arco/Libros.

HeAton H. C. (1927): "A volume of rare sixteenth century spanish dramatic works». Romanic Review, 18, 339-345.

Karlinger, F. y PöGL, J. (1992): Totentenz und Froleichnamsspiel: «Farsa llamada dança de la muerte» von Juan de Pedraza. Salzburg: Institut für Romanistik der Universität.

Mujica Láinez, M. (1974): Misteriosa Buenos Aires. Buenos Aires: Sudamericana, 17-22.

PÉReZ Priego, M. Á. (2011): «Alfonso de Castrillo, Tres Passos de la Pasión y una Égloga de la Resurrección». Lemir, 15, Textos, 275-302.

PÉREZ PRIEGO, M. Á. (2012): «Fernando Díaz, Farsa nuevamente trovada en loor del Nascimiento». Lemir, 16, Textos, 569-584.

Pérez Priego, M. Á. (2013): «(Pedro de?) Salazar, Égloga de Breno y otros tres pastores». Lemir, 17, Textos, 979-985. 
Pérez Priego, M. Á. (2017): «La colección de piezas dramáticas de los Fugger», en Pedraza, F. B. et al. (eds.): Drama y teatro en tiempos de Carlos I (15171566). Almagro: Ediciones de la Universidad Castilla-La Mancha (Corral de comedias, 40), 191-205.

Pérez Priego, M. Á. (2018): «Juan de París, Farsa». Lemir, 22, Textos, 649-680.

WEBER DE KURLAT, F. (1965-1966): «La imprenta en que se editó la Recopilación en metro de Diego Sánchez de Badajoz». Nueva Revista de Filología Hispánica, 18, 156-160.

Weber De Kurlat, F. (ed.) (1968): Diego Sánchez de Badajoz. Recopilación en metro (Sevilla, 1554). Buenos Aires: UBA.

Miguel Ángel PÉREZ PRIEGo Universidad Nacional de Educación a Distancia mperez@flog.uned.es https://orcid.org/0000-0002-3571-2169 
